Brit. J. vener. Dis. (1955), 31, 210.

\title{
VALUE OF THE KAHN TEST IN AFRICANS*
}

\author{
BY \\ A. J. EVANS \\ Fort Jameson, Northern Rhodesia
}

Stokes, Beerman, and Ingraham (1944a) discussing the occurrence of biologic false positive (BFP) results with serological tests for syphilis, wrote :

Inevitably, faith in the positive is being undermined and, with it, the tremendous positive efficiency and low margin of error of serologic test procedure for syphilis in the aggregate is momentarily submerged.

This observation is even truer today.

Originally it was believed that the various standard tests were specific for syphilis, and that the finding of a positive test was proof that the patient had syphilis. The fact that the tests could be undertaken with a non-specific antigen extracted from beef-heart, raised doubts as to the specificity of the tests. It subsequently became apparent that positive results were sometimes obtained from patients other than syphilitics, and, with the passing of years, more and more causes of false positives have been reported, together with reports of false positives for which no cause could be ascribed, so that now there is a formidable literature on the subject. The British Journal of Venereal Diseases (1951), in an editorial devoted to the subject, suggested that the increasing awareness of the problem of the BFP could be ascribed to two causes :

(i) The mass blood testing of blood donors, antenatal patients, etc., which had become common during and since World War II.

(ii) That the general sensitivity of serum testing might have risen to such a degree as to endanger specificity.

When serological tests for syphilis (STS) were carried out only on those who definitely had, or who were suspected of having, syphilis, then obviously the opportunities for observing false positives were few. With the advent of mass testing, and, in some countries, of compulsory marital and pre-enlistment testing, the opportunities of observing false positives became greatly increased and many serologists, to avoid the false negative result, have introduced modifications to increase sensitivity.

The consensus of opinion is that such false positives do occur, and are not due to masked

\footnotetext{
* Received for publication May 13, 1955.
}

syphilis. But Heywood (1952), in a paper read before the Medical Society for the Study of Venereal Diseases, stated that :

Experience has proved that, whatever their fundamental nature, present-day serological tests for syphilis are, in practice, both highly sensitive and highly specific; and with appropriate safeguards to exclude temporarily false positive reactions, a positive reaction means that the patient has been infected with syphilis at some time in his life.

He further considered that the concept of biologic false positive reactions had no practical importance. That Heywood's views were not generally acceptable was obvious during the discussion that followed his paper.

\section{Problem of the BFP Reaction}

Definition of the BFP Reaction.-Price (1949) defines BFP as " the repeatedly positive blood test given by the serum of a patient who fails to yield any evidence of the disease [syphilis]".

Moore and Mohr (1952a and b) further subdivide $B F P$ reactions into the following categories :

(a) Acute BFP reactions which occur during or shortly after a variety of non-syphilitic infections and disappear spontaneously within a few days, weeks, or months.

(b) Chronic BFP reactions wherein reagin persists in the blood over many months or years, perhaps even for life.

Value of Different STS.-Opinions are very varied as to the specificity of the different forms of STS : Kvittingen, Cutler, McCullough, Rose, Ford, Tampi, Sen, and Lakshwir (1952), reporting from India on parallel testing with the Qualitative Kahn, the Meinicke, and the VDRL tests, recorded " remarkable agreement " between them. Schmidt (1953), reporting from Copenhagen on a series of 5,250 presumably non-syphilitic patients, found the incidence of BFP reactions with the Wassermann using lipoidal antigen higher than with the standard Kahn test, which had the same specificity as the Wassermann with cardiolipin antigen. Wilkinson (1954), using the treponemal immobilization (TPI) test as a yardstick, found the specificity of various STS to be in the following order :

(i) Price Precipitation Reaction,

(ii) Standard Wassermann,

(iii) Kahn,

(iv) Cardiolipin Wassermann. 
Moore and Mohr (1952a) summarize the position thus :

Although it is customary for each author-serologist to claim that his test has some special virtues that set it apart from others, it is none the less true that all of these tests depend on a basically identical physicochemical and immunological phenomenon.

Since all STS depend on the same phenomenon, and a non-specific one at that, it seems probable that all of them will be more or less liable to BFP reactions.

Value of Verification Procedures.-Various attempts have been made to recognize a specific antibody of syphilis among the complex of substances collectively known as reagin, the presence of which in the serum is the basis of all the different STS. Attempts to show whether reagin produced in treponematoses and in BFP reactions are qualitatively identical have so far failed. The two best known verification procedures are the Kahn verification test and the Neurath euglobulin inhibition phenomenon, neither of which has been found to be satisfactory. Falcone, Harris, Olansky, Salvado, and Cutler (1953) tested the Neurath inhibition phenomenon on 436 patients in Guatemala and found that the results were dependent to a large extent on the type of antigen used, and that it added no significant information to that given by STS. Roy, Hill, Gowdey, Kelcec, and Rein (1953) compared results with the Neurath phenomenon and the TPI test in a series of 96 patients, including known syphilitics, problem cases, and presumed non-syphilitics. They found that the Neurath test was in agreement with the clinical diagnosis in only 64.5 per cent. of the cases, whereas the TPI test was in agreement with the clinical diagnosis in 95.7 per cent. of them. That is to say, the clinical diagnosis was a better guide to the presence of syphilis than was the Neurath phenomenon. Harrell (1953) compared the results of the TPI and Kahn verification tests in 48 problem sera (diagnosed clinically as BFP, having positive STS, and no history, signs, or symptoms of syphilis). He found that the results of the Kahn verification test differed from the TPI in 30 per cent. of cases. Rein and Kostant (1949) state that the Kahn verification test has been unable to distinguish consistently between positive and false positive serological reactions. Moore and Mohr (1952a) state that the Kahn verification test and the Neurath phenomenon have no practical merit. Kolmer and Lynch (1953) express a similar opinion.

Value of Special Antigen.-The isolation of cardiolipin, a serologically active phospholipid, from beef heart by Pangborn (1941) was hailed as a great step forward, as it was hoped that the replacement of the relatively crude heart extracts, from which the lipoidal antigens are manufactured, by pure cardiolipin would eliminate the occurrence of BFP reactions.

It is generally accepted that the use of cardiolipin antigens has made the STS more specific. Andujar, Anderson, and Mazurek (1948), reporting their experience with 24,609 blood samples, commented on the generally superior specificity with cardiolipin antigens, though they noted BFP reactions with cardiolipin as well as with lipoidal antigens. Kolmer and Lynch (1953) state that cardiolipin antigens are less likely to give BFP reactions, and stress that this is particularly so in malaria. Klein and Leiby (1948) reported that six (26 per cent.) of 23 cases of malaria gave positive Kahn results, while with tests using cardiolipin antigen no positives were found. Stout and Cutler (1951), working in Guatemala, found a much higher proportion of positives using lipoidal antigens (Kahn and Mazzini tests) than with cardiolipin antigens (VDRL and Kahn tests). Stout, Guzmán, and Scrimshaw (1952a) subsequently examined children from a number of Central American schools (only one of which was in a malarious district), using a battery of tests. Not every child was submitted to all the tests, but between 1,500 and 2,000 sera were submitted to each test. They found the following positive results with lipoidal antigens: Mazzini 33.2 per cent., and Kahn $17 \cdot 4$ per cent., whereas with tests using cardiolipin they found: VDRL test 2:6 per cent. positive and Kline $3 \cdot 1$ per cent. positive. There was no evidence of a high incidence of congenital or of latent acquired syphilis among the children. They therefore concluded that there was a much higher incidence of BFP results using lipoidal antigens. Levitan, Aragon, Cutler, Funes, Portnoy, and Paredes (1952) reported similar findings with 438 children from a Guatemala orphanage. Idsoe, Guthe, Christiansen, Krag, and Cutler (1954) commented on the tendency for cardiolipin antigens to give fewer BFP reactions. Tompkins (1949) carried out STS on non-syphilitic patients 2 weeks after successful vaccination, and concluded that BFP reactions were commoner with lipoidal than with cardiolipin antigens, and with precipitation than with complement-fixation tests. Klein, Konwaler, Sears, Berke, and Leiby (1950), however, having examined 8,851 presumably non-syphilitic sera by the lipoidal Kahn test and a cardiolipin slide test, found no difference in the specificity of the two tests, both being in the region of 99 per cent. Price (1954) concluded that the liability to obtain non-treponemal reactions was greater when using cardiolipin-type antigens than when ordinary standard antigens are used. Stout, Harris, and Olansky (1954), summarizing the position of STS in the U.S.A. in 1954, state that the only lipoidal test still favoured is the Kahn test. They stress that, though cardiolipin antigens will reduce the incidence of BFP reactions, they will not entirely eliminate them.

More recently, claims have been made for the use of another phospholipid, sitolipin, extracted from soya bean. Pirilä (1954), testing a sitolipin antigen in the VDRL test against the standard Kahn using lipoidal antigen in 1,535 patients who had been thoroughly examined clinically, found fewer BFP reactions with the sitolipin test than with the Kahn test. Rein, Kelcec, and Rosenfield (1951) compared the results with sitolipin and cardiolipin antigens in three different STS (VDRL, 1,682 sera; Rein-Bossak, 1,798 sera ; and Kent complement-fixation, 624 sera). They obtained practically identical results whatever type of antigen was used.

Value of Using Several Tests.-It has been repeatedly observed that, where BFP reactions occur, they often do not show positive in all of a battery of different 
tests. Schmidt (1954), reporting on the results of routine STS on blood donors in Copenhagen, concluded that when several or all of a battery of STS were positive this was strong evidence of syphilis as opposed to BFP reactions. Kolmer and Lynch (1953) advise the use of two or three tests " since there is as yet no best serological test for syphilis". Stokes and James (1949), discussing their experience with 43 BFP cases, advise the use of a battery of tests, and describe serological discord as a warning of probable BFP reaction, though they point out that serological discord is also found in syphilis after previous treatment. Thomas, Landy, and de Mello (1950) also commented on the occurrence of serological discrepancies, noting them particularly when the results with flocculation and complement-fixation tests were compared, but they observed such discrepancies both in BFP reactions and in true syphilitic cases.

Treponemal Immobilization Test.-Until the description of the treponemal immobilization (TPI) test by Nelson and Mayer (1949), all serological tests for syphilis depended on the demonstration of the presence of non-specific reagin. The TPI test depends on the detection of a treponemal antibody distinct from reagin. Early reports suggested that it was highly specific, positive results only being obtained from patients with syphilis or allied treponematoses. Subsequent reports have not contradicted the original opinions as to the value of the TPI test, not only with regard to specificity but also in reproducibility.

Magnuson and Thompson (1949) and Thompson and Magnuson (1951) reported on the specificity of the TPI test and its value in recognizing BFP reactions. Nelson and others (1950) reported that fifty patients clinically diagnosed as having latent syphilis all gave positive TPI tests, and twelve patients who were clinically BFP cases all gave negative TPIs. Miller and others (1952a, b; 1954) reported on their experience with 455 TPI tests and commented on its specificity and value in recognizing BFP results. Chacko (1953) showed experimentally that the immobilizing antibody was stable under varying conditions of temperature and serum contamination, a most important point if specimens are to be sent from a distance, particularly in the tropics. Chorpenning (1953) reported the specificity of the TPI test as 99 per cent. or over. Olansky, Harris, and Hill (1953), using the TPI test in the elucidation of BFP reactions in patients inoculated with malaria, obtained confusing results which they ascribed to poor reproducibility of the TPI test. Roy and others (1953) and Boak, Miller, and Carpenter (1954) both reported a high degree of reproducibility of the TPI test $(97 \cdot 4$ per cent. in Boak's series) in contradiction of Olansky's findings. Wheeler, Van Goor, and Curtis (1954) reported a reproducibility of 93 per cent. and 96 per cent. with the TPI test, and also commented on its specificity and value in elucidating BFP results. Nielsen (1954) and Zellmann (1954) made similar comments.

The drawbacks to the TPI test are technical complexity and expense. Its satisfactory performance necessitates a highly skilled team of laboratory workers permanently on guard against errors. Ledbetter (1954), discussing the use of the TPI test in the United States Navy, has stressed the necessity of training and maintaining such a team. While some technical simplifications have been introduced since Nelson's description of the technique, the TPI test still remains a most complicated laboratory procedure and one which cannot be attempted in any but the best-equipped and staffed laboratories. It also remains an expensive test, and the cost alone will preclude its wide use in most backward countries. Nielsen (1954) estimated that only thirty laboratories throughout the world were performing the TPI test as a routine. Possibly the immune adherence test recently reported by Olansky, Harris, and Casey (1954) or some other similar test simpler than the TPI may prove the ultimate answer. The present position is that, though the TPI test is the answer to the problem of the BFP reaction, it is not a practical proposition in many world areas, particularly in the tropics. Moore (1949) says :

Though Nelson's work on treponemicidal antibody is of the highest importance to the eventual development of a wholly new, more sensitive, and perhaps absolutely specific serological test for syphilis, it is certain that at least for the next decade reliance must still be placed on the present non-specific lipoidol antigens for the detection of the equally non-specific reagin.

Probably "decade" is an underestimate for many world areas.

\section{NATURE OF BFP}

Technical False Positive.-Kolmer and Lynch (1953) point out that many BFP reactions are due to technical errors in the taking of specimens, in the performance of the STS, or in the reagents used. Technical false positives are especially liable to occur in backward countries where much of the taking and labelling of blood specimens, book-keeping, care of glassware, etc., has to be undertaken by semi-skilled or unskilled personnel. Lees (1951), discussing the problems of venereal disease in Africa, stressed the need for a simple serological test for syphilis of high reliability which could be done by an African technician. He also stressed the need for trustworthy batches of antigen. Kvittingen and others (1952) reporting from India, mentioned the variability of different batches of antigen as a cause of anomalous results. Idsoe and others (1954) state that :

Most variations in sensitivity and false positivity result from individual differences both in the patient and in the test procedures rather than in the under-

lying differences in the process being tested for the behaviour of the reagin.

One other factor of special importance in the tropics is the tendency of sera to deteriorate when they have travelled long distances, especially under adverse climatic conditions (Evans, 1954). Kahn (1954) considered that he could distinguish a typical serological pattern in yaws, but subsequently found that this only occurred in sera which had travelled long distances (i.e., from Jamaica), and was not present in fresh sera from yaws patients.

Most technical false positives (and negatives) can be readily eliminated in all cases with anomalous results 
by repeating the test or tests on a second fresh specimen of serum with different antigen and possibly at a different laboratory. The occurrence of frequent anomalous STS results at a laboratory is an indication for a careful review of technique and technicians, a check on the purity of all reagents used, and for testing the antigen in use against a standard antigen (if possible from the author-serologist's laboratory).

Strength of BFP Reactions.-The belief that BFP reactions were characteristically of low titre was at one time widely held. Allison and Dick (1954), reporting a case of a BFP result associated with virus pneumonia, state that BFP reactions are usually weak, and a strongly positive reaction is often regarded as being caused by syphilis unless proved otherwise. Schmidt (1954), reporting on BFP reactions among blood donors, found the greatest number of them among the lower degrees of potency. Kahn (1954) states that BFP reactions are usually weak and of low titre. Stokes and James (1949), however, reviewing their experience with 43 BFP reactions from private practice, found quite a high proportion had high titres with STS.

The advent of the TPI test has cast further doubt on the generalization that BFP reactions are only weakly positive to STS. Miller, Slatkin, Brodey, Weschsler, and Hill (1954) concluded that the serological titre was of no certain significance in excluding BFP results, since patients with high serological titre were sometimes found negative to the TPI test and vice versa. Wilkinson (1954) found that, while a majority of BFP reactions (confirmed by TPI testing) are low-titred, there are sufficient with high titres to make any generalization unwise. Wheeler and others (1954) made a similar observation.

Duration of BFP Reactions.-Kolmer and Lynch (1953) state that most BFP reactions become negative in 3 to 6 months, sometimes in a few days. Price (1949) found that on serial testing, the reaction remained positive for a relatively short time, and gradually subsided to negativity without treatment. Kahn (1954) states that BFP reactions may continue for a few weeks to several months. It is probable that, as suggested by Thomas and others (1950), falling titres which become negative in untreated patients who deny the possibility of syphilis are rarely, if ever, due to syphilis. However, their further statement, that positive STS results which do not show a declining titre in the absence of syphilitic treatment mean, in the majority of cases, that the individual has or has had syphilis, would not be generally accepted now. In short, an STS result that becomes negative in a short time without treatment is almost certainly a BFP reaction, but no conclusion can safely be drawn that, because the tests remain positive for months or years, the patient therefore has syphilis.

BFP Reactors.-Kahn (1950a, 1953, 1954) has described his universal serological reaction. By this test, which is a series of quantitative set-ups with different concentrations of saline solution and read after different periods of incubation in the refrigerator, he describes a serological pattern for health and in certain diseases. $\mathrm{He}$ states $(1950 \mathrm{c})$ that in certain normal healthy individuals the serological pattern comes very close to the serodiagnostic zone, and that such individuals are particularly liable to give false positive reactions. Stokes and James (1949) also state that some individuals tend to produce reagin more easily than others, i.e., are BFP reactors. They also suggest that, when a syphilitic has gained sero-negativity, he may again become positive under the influence of agents, such as inoculation, malaria, etc., which tend to cause BFP reactions.

Other Factors in BFP Reactions. - A wide variety of conditions has been shown in the past to be associated with the occurrence of BFP reactions. It is believed that almost any condition which causes tissue breakdown may result in a BFP reaction in individuals prone to give such reactions (BFP reactors). The most common causes of such BFP reactions are acute infections of which outstanding examples are infectious mononucleosis, pneumonia (especially virus pneumonia), influenza, scarlet fever, typhus, meningitis, tuberculosis, relapsing fever, rat-bite fever, Weil's disease, typhoid fever, trypanosomiasis, kala-azar, and especially malaria. The BFP reaction in such cases usually requires, according to Kahn (1954), about 2 weeks' incubation after tissue breakdown has commenced. It is of the acute type described by Moore and Mohr (1952a), and becomes negative in a short time without antisyphilitic treatment. Of similar nature is the BFP reaction occasionally found after inoculation, especially vaccination and inoculation against yellow fever or typhoid. Talmage, Dunn, and Breazeale (1946) found that of 692 battle casualties, 253 (34.5 per cent.) had a positive STS, in only one of which was syphilis thought to be the cause.

Both jaundice and cirrhosis of the liver are quoted as occasional causes of BFP reactions. However Stout, Aguirre, and Scrimshaw (1952) could find no correlation between the occurrence of BFP reactions and of positive cephalin cholesterol flocculation tests for liver function among school children in Central America. Similarly, it has been suggested that hyperproteinaemia might be associated with BFP reactions. Stokes, Beerman, and Ingraham (1944b) give the incidence of BFP reactions in hyperproteinaemia as 23 per cent. Wills and Bell (1951) found a high proteinaemia among the natives of Fiji and also a high rate of positive STS ; they mention however that yaws is common. Cardon and Atlas (1942) found that electrophoretic studies did not corroborate the belief that BFP reactions are associated with hyperproteinaemia. Cooper, Craig, and Beard (1946) could find no basis for the diagnosis of syphilis by electrophoretic analysis of sera, or for a differentiation between individual syphilitic and BFP sera. Stout, Méndez, Guzmán, and Scrimshaw (1952) could find no relation between the level of serum proteins, albumin-globulin ratio, or level of $\alpha-, \beta$-, or $\gamma$-globulin and the occurrence of BFP reactions in school children in Central America.

Evidence as to the possible effect of dietary deficiencies in causing BFP reactions is conflicting. Meinicke (1952) reported converting presumptive BFP reactions to negative in undernourished patients by the oral administration of lecithin. Stout, Guzmán, and Scrimshaw (1952a) 
did a battery of STS on school children in Central America, then administered extra protein in the diet in the form of a mid-morning " snack" for a year, together with treatment for intestinal parasites. At the end of this time they repeated their battery of STS and found no significant change in the percentage of sero-positivity. They also estimated serum-levels of carotene, vitamin A, and vitamin $\mathrm{E}$ among the children and found a lower level for all three (though not below the limits of normality) among children who gave BFP reactions with lipoidal antigen than among those children who were negative to STS with lipoidal antigen. They consider that the lower values are not the cause of the BFP reactions, but that some common factor is the cause of both BFP reaction and low serum levels of carotene, vitamin $A$, and vitamin E. All these are fat soluble factors and must be carried in the blood in relation to serum lipids or lipo-proteins.

While the causes of the acute BFP reactions are numerous and well known, the cause of chronic BFP reactions with long duration is less certain. Moore and Mohr (1952a, b) mention leprosy as one disease which may cause this type of BFP reaction. They also stress that the collagen diseases, such as disseminated lupus erythematosus, periarteritis nodosa, rheumatoid arthritis, rheumatic fever, and sarcoidosis, are common causes of chronic BFP reaction. Of particular interest is the fact that the STS may become positive long before the precipitating disease is clinically apparent.

In quite a high proportion of cases no cause can be found to account for the BFP reaction. Minute amounts of reagin are present in sera from all normal persons, and in a few healthy persons it is present in sufficient amounts to produce positive results in STS (Moore and Mohr, 1952a). Durel, Saussé, and Borel (1952), reporting on their experience using the TPI test in 1,000 cases, state that the origin of the BFP reaction was rarely found, most of their patients being healthy at the time and having nothing significant in their histories. Nelson (1952), reporting on patients found to have BFP reactions by the TPI test in the United States Navy, could find no known factors responsible for the BFP reactions in 74 per cent. of them. Wilkinson (1954) could find no cause for the BFP reaction in the majority of his TPIproven cases. Wheeler and others (1954), working with the TPI test, found that, when a specific cause for acute BFP was present in a patient with a positive STS only, then 78 per cent. were true BFP reactions, whereas, when no aetiological condition was found, only 53 per cent. were BFP reactions.

Incidence of BFP Reactions. - The published reports on the incidence of BFP reactions can be divided into those obtained by mass blood testing, and those from clinic, hospital, and "problem" patients. The latter comprise, of course, a selected group. The reports can further be divided into those in which the diagnosis of BFP reaction was confirmed by the use of the TPI test, and those in whom the diagnosis was made solely on clinical, epidemiological, and anamnestic grounds.

Of the reports on unselected groups, Wolman (1946) studied routine serological tests on 82,070 consecutive maritime entrants from all over the United States.
Nearly all of them were white, but otherwise they were unselected. He found an incidence of presumed nonsyphilitic positives of 1 in 790 ( $0 \cdot 13$ per cent.). Schmidt (1954) reported an incidence of BFP reactions of $0.3 \mathrm{per}$ cent. among blood donors in Copenhagen. Eagle (1941) found the incidence of BFP reactions among 40,545 American college students to be ten (0.024 per cent.). Stokes, Boerner, Hitchens, and Nemser (1946) found among 210,261 blood donors in Philadelphia an incidence of BFP reactions of 0.14 per cent. In an editorial on BFP reactions (Lancet, 1954), it was computed that the proportion of non-treponemal reactions with STS was about 1 in 2,500 (0.04 per cent.). Hinton, Stuart, and Grant (1949), using Hinton's own test, reported the results of routine testing on 6,325 prospective blood donors in Massachusetts. They estimated the percentage of BFP reactions as 0.2 to 0.3 . Thus in presumed nonsyphilitics in mass surveys the incidence of BFP reactions varies between 0.04 and 0.3 per cent.

Among the reports of selected groups, Kahn (1953) states that, in official serological evaluations under the auspices of the United States Health Services, of 2,833 samples tested from non-syphilitic persons (excluding malaria and leprosy) he has not had a single BFP reaction with his test. Price (1949), reporting $\bullet$ on 8,276 sera tested routinely from a London clinic, found the incidence of BFP reactions to be $\mathbf{0 . 0 8 5}$ per cent. with the Wassermann reaction, and 0.01 per cent. with the Price Precipitation reaction. Klein and Leiby (1948) found, among 3,626 presumed non-syphilitics from hospital and unselected groups, that the incidence of BFP reactions was 1.16 per cent. with the Kline cardiolipin slide test, and 0.58 per cent. with the Kahn test. Schmidt (1953) found the incidence of BFP reactions to vary between 0.5 and 0.7 per cent., among 5,250 non-syphilitic patients from hospital and antenatal practice. Thus the reported incidence of BFP reactions among hospital and clinic patients varies from 0.01 to 1.16 per cent.

Stokes and James (1949) state that " the proportion of biologic or non-specific positives in a series of routine positives may approach 40 per cent.". Moore and Mohr (1952a), reported on experience with the TPI test that

In certain population groups in the United States (especially in white persons of relatively high socioeconomic state in the North-eastern, Northern and North-western states), at least half of the sero-positive reactors discovered in mass-blood-testing programs do not have syphilis at all.

Again, Moore and Mohr (1952b) report that of 300 white patients seen in private practice who had persistently positive STS and no other signs, symptoms, or history suggestive of syphilis, 136 (45 per cent.) were TPI negative. Ledbetter (1954) reported that of 1,933 sera from patients in the United States Navy, submitted for TPI test because the serological result was not in keeping with the clinical findings, 42.4 per cent. were TPI-negative. Nelson $(1952,1953)$ reported two series of 529 and 496 patients who were STS-positive but without history, signs, or symptoms of syphilis. Of these, 42 per cent. and 42.5 per cent. respectively were TPInegative. Wilkinson (1954) reported an incidence of 
29.7 per cent. TPI-negative among 209 " problem" sera submitted to the V.D. Reference Laboratory, London. However, with sera of patients with presumed latent syphilis (positive STS but no other evidence of syphilis) from a London clinic, he found the TPI test negative in 4.8 per cent. of 42 untreated cases and 5.5 per cent. of ninety treated cases.

Wheeler and others (1954) performed the TPI test on 733 sera from individuals who had had at least one, usually two or more positive STS reactions. They describe them as patients in whom the clinical and serological findings were such that a definite diagnosis was impossible. Of these, $46 \cdot 1$ per cent. were TPI-negative. They make the further interesting observation that, when a tentative diagnosis had been submitted with the specimen, of 173 TPI-positive sera, only 81 (47 per cent.) had been tentatively diagnosed as syphilis, whereas of 199 TPI-negative sera 164 ( 83 per cent.) had been tentatively diagnosed as BFP results. These figures illustrate well the increasing tendency to regard as nonspecific those positive STS reactions unassociated with obvious evidence of syphilis. Thus the reported incidence of false positivity among patients having repeatedly positive STS and no other evidence of syphilis varies between 4 and 46 per cent.

\section{The Problem in the Tropics}

Most of the work on the incidence and nature of BFP reactions has been done in a temperate climate, with the exception of the intensive study from Central America (Stout and Cutler, 1951 ; Stout, Aguirre, and Scrimshaw, 1952; Stout, Méndez, Guzmán, and Scrimshaw, 1952 ; Stout, Guzmán, and Scrimshaw, 1952a, b ; Levitan and others, 1952). It is, however, generally assumed that the incidence of BFP reactions under tropical and sub-tropical conditions will be materially higher than in temperate climates. Roy and others (1953) state :

Recognition of biologic flase positive serological tests for syphilis has become of great importance. This is true not only in such countries as the United States, but even more in rtopical countries, such as India, in which there are relatively high incidenced of malaria, leprosy, and other diseases in which biolog!c false positive tests are known to occur.

Willcox (1952), discussing the incidence of neurosyphilis in Africans, mentions the frequency of false positive reactions to STS in a malarious country. The World Health Organization SubCommittee on Serology (1950) state :

There is some evidence to support the belief that the prevalence of the disease (syphilis) in some world areas has been greatly exaggerated, being based on the high proportion of positive serological findings. It is very possible that this picture is the result of an environmental condition quite distinct from syphilis.

Mahoney and Zwally (1949), commenting on the high incidence of positive serological findings which have been reported from some tropical areas, suggest that unrecognized environmental factors may be responsible for a serological picture entirely at variance with the frequency with which syphilis is encountered. Levitan and others (1952) make a similar suggestion. Unfortunately, the laboratory facilities needed to unravel this problem are most deficient in the very areas where the problem is most pressing. Rein (1952), discussing the serodiagnosis of yaws, commented that " sero-diagnostic facilities were least where yaws is most common ". With the general fall in the incidence of syphilis in Europe and the United States of America, the same might now be said of syphilis.

With such a wealth of published opinion expressing doubts on the efficiency of STS in the tropics and sub-tropics, it is not surprising that a tendency is growing in Africa to disregard a positive STS result, in the absence of obvious signs of early syphilis, without first attempting to establish the diagnosis on anamnestic and epidemiological grounds and in the light of the results of physical examination. Sachs and Selesnick (1953), discussing their experience among Africans in Johannesburg, make the generalization that STS of low titre should not be treated, with the exception of pregnant women. Macnab and Murray (1953), commenting on this work of Sachs and Selesrick, state :

Intensive investigation is required into the question whether the Bantu (African) reacts to reptonemata in the same way as the European and, above all, whether the positive serological reactions so frequently found among them can, in the majority of instances, be equated with a treponemal infection.

It was in an attempt to investigate the relation of a positive serological reaction to the presence of treponemal infection in Africans that the present investigation was made.

\section{Present InVestigation}

The present investigation is based on the findings in 6,797 successive new adult African patients attending at eight different V.D. clinics held at regular intervals at scattered points throughout the Eastern Province of Northern Rhodesia during 1953 and the early months of 1954 . A routine qualitative Kahn test was performed on each new adult patient, irrespective of the reason for attending the clinic. They were also subjected to a physical examination, often under difficult conditions as clinics are held in any building that happens to be available. Dark-ground examinations were performed on all patients with primary and secondary syphilis (with very rare exceptions, such as the man with the chancre beneath a phimosed prepuce or 
the woman who was menstruating), and smears examined for gonococci from all men with a urethral discharge and from every woman. Facilities for performing culture examinations were not available. In every case where the Kahn result did not fit in with the clinical findings it was repeated at the next visit (in 1 or 2 weeks), as advised by Rein and Elsberg (1944). In this way it was hoped to eliminate the bulk of technical false positives due to faulty labelling or handling of specimens. All specimens were in the refrigerator within 36 hours of being taken and were tested within a further 36 hours. None of the specimens was brought more than 150 miles by road.

The technique used in the performance of the Kahn test was exactly as described by Kahn (1950d). The antigen used was of several batches obtained from the South African Institute for Medical Research, Johannesburg. This antigen was usually excellent, but, on the rare occasions when any doubt was felt about the reliability of a particular batch of antigen, it was tested in parallel with another test (either the Eichorn-Rappaport or Price Precipitation reaction), and if doubt still existed the batch was discarded. The standard Kahn test was used in this investigation not because it was felt that it had any special virtue over other tests, but because it is the routine serological test for syphilis most commonly used throughout Central Africa. It is felt that, in view of the diverse opinions as to the value of the different tests in common use, there is no justification for changing the test already established. Best results will probably be obtained with the test with which a laboratory is most familiar.

Of the total of 6,797 patients, 791 had to be excluded from the analysis because they failed to attend for repetition of serological tests, because details of history were not recorded, or because for some other reason the diagnosis could not be ascertained. Details of the remaining 6,006 patients, together with the results of their Kahn tests, are given in Table I. For the purposes of this analysis the Kahn results are classified as :

(i) Positive $(++++,+++$, or ++ according to Kahn's method of reading),

(ii) Weak positive $(+$ and \pm$)$,

(iii) Negative.

All cases with clinical signs of syphilis, other than in the primary, secondary, and congenital stage, have been classified as late syphilis without reference to stage or system involved. It should not be assumed that these figures indicate the relative incidence of early (primary and secondary) syphilis and of late syphilis. The average African does not
TABLE I

KAHN RESULTS AND SYPHILITIC STATE

\begin{tabular}{|c|c|c|c|c|}
\hline $\begin{array}{l}\text { Clinical } \\
\text { Findings }\end{array}$ & & Positive & $\begin{array}{l}\text { Weak } \\
\text { Positive }\end{array}$ & Negative \\
\hline Primary syphilis & $\cdots$ & 282 & 227 & 194 \\
\hline Secondary syphilis & $\cdots$ & 493 & 18 & 一 \\
\hline Late syphilis. . & $\ldots$ & 23 & - & - \\
\hline Congenital syphilis & & 4 & 3 & 1 \\
\hline Other. . & $\cdots$ & 900 & 987 & 2,870 \\
\hline Total $(6,006)$ & $\ldots$ & $\begin{array}{c}1,702 \\
(28 \cdot 3 \text { per cent. }\end{array}$ & $\begin{array}{c}1,239 \\
(20 \cdot 6 \text { per cent. })\end{array}$ & $\begin{array}{c}3,065 \\
(51 \cdot 1 \text { per cent. }\end{array}$ \\
\hline
\end{tabular}

recognize the nature of the late manifestations of syphilis, particularly neurosyphilis and cardiovascular syphilis, and will go to the hospital rather than to the V.D. clinics. Such cases are therefore usually seen at the hospital, and do not pass through the books of the V.D. clinics. The same is true to a lesser extent of congenital syphilis in adults, though late manifestations of congenital syphilis in Africans are rare, as pointed out by Willcox (1949) from Southern Rhodesia.

As is shown in Table $I$, the results of the Kahn tests in the patients with overt manifestations of syphilis are in complete agreement with the clinical findings. Of 705 cases of primary syphilis 40 per cent. were positive, 32 per cent. weak positive, and 28 per cent. negative. Of 511 cases of secondary syphilis, 96 per cent. were positive, 4 per cent. weak positive, and none negative.

Of the 3,065 patients with negative Kahn tests, 194 had early primary syphilis, 915 had gonorrhoea, twenty non-specific urethritis, fifteen lymphogranuloma inguinale, ten chancroid, one granuloma venereum, three had a simple balanitis, and 25 gave a definite history of syphilis which had been adequately treated. A further 93 patients with negative Kahn tests complained of repeated abortions but had no other history or symptoms suggestive of syphilis. In the remaining 1,789 patients with negative Kahn no evidence of any form of venereal infection could be found. Quite a number of them were antenatal cases, some came with a variety of skin diseases which they thought might be of venereal origin, a very large number came because of dysuria due to bilharzia which they thought was of gonococcal origin and the remainder "came to make sure ". These cases are largely the by-product of several years of intensive propaganda as part of the general measures against venereal disease in this area.

There remain 1,889 patients (869 men and 1,020 women) who repeatedly gave positive or weak positive Kahn reactions and in whom no overt 
signs of syphilis or other treponematosis was found. These patients, 31.5 per cent. of the total analysed, are of special interest, since any or all of them might be BFP reactors.

Nelson, Zheutlin, Diesendruck, and Austin (1950) diagnosed latent syphilis on the following criteria :

(i) history of suggestive early lesions or repeated exposures to cases of early syphilis,

(ii) persistently positive STS for several months in the absence of known possible causes of BFP reaction.

They excluded late syphilis by the absence of clinical manifestations and the finding of a normal cerebrospinal fluid. Their fifty untreated patients conforming to these criteria all gave positive TPI tests.

The criteria used here have, of necessity, had to be less stringent for the following reasons:

(a) Every one of these patients will have had malaria (a known possible cause of BFP reaction), not once but many times.

(b) It is impossible to estimate which of the patients had been exposed to cases of early syphilis. Willcox (1949) has given a very excellent account of the promiscuity of the African in Southern Rhodesia. Much the same applies in the Eastern Province of Northern Rhodesia. The African Affairs Annual Report for 1953 (Northern Rhodesia, 1954) shows that 1,015 adultery cases and 2,407 divorce cases were heard before the Native Courts in the Eastern Province. Of the divorce cases about 70 per cent. were for adultery, which makes a total of 2,699 adulteries among 102,901 adult men. It is doubtful whether as much as 5 per cent. of the actual adulteries that occur ever come to the notice of the Native Courts.

(c) Lumbar puncture was not performed on these patients. At most of the rural clinics where many of these patients were seen, facilities were not available for this examination. In any case, experience has shown that, except when he has a well-marked neurological lesion, the African is most unwilling to submit to lumbar puncture, and that, if the matter is pressed, the patient and most of his friends simply default. Kvittingen and others (1952) from India have described what happens when an unpopular measure is pressed among backward peoples.

\section{Method of Assessment}

In attempting to decide whether or not a persistently positive Kahn reaction was or was not due to syphilis, the following points have been investigated :

(i) History.-African memories are admittedly short, but the large majority of Africans can remember the occurrence of genital sores, particularly if they were followed by a few painful injections. As to the date of the infection they are often much less certain and the usual answer to this question is "last year" or "long ago ", neither of which has very much relation to the calendar. It should be stressed that accurate histories are much more likely to be obtained when the examiner is well known and has been in the district for some years.
It has usually been accepted that, where a positive STS reaction is associated with a definite history of syphilis, the STS is a true and not a false positive. Rein (1952), however, discussing the value of anamnestic evidence in the diagnosis of yaws, suggests that it is fraught with danger, since " the news soon gets around among the natives that they will receive some 'magic medicine' if they say they have had yaws, and this they will gladly do with the hope that it will cure their bone pains and malaise, as well as many imaginary ills". This is a point of very real importance, but it can be discounted in the series under investigation, as it has never been the practice to give treatment on the history of syphilis only.

It is true that the genital sores may not have been syphilitic, but the causes of genital sores other than syphilis are rare and it can safely be assumed that the vast majority of patients who gave such a history did in fact have syphilis.

(ii) Scars.-Usually in the European the lesions of early syphilis heal without scarring. This is not true of Africans, for a variety of reasons. De Mello (1948) has given an excellent description of how the typical chancre in Africans becomes secondarily infected with pyogenic organisms. Most patients apply various " native medicines "locally to the lesions, whether or not they are having Western medicine at the same time. Many of these native medicines are vegetable astringents, and not a few of them include cow-dung among other ingredients. It is therefore not surprising that the lesions become secondarily infected and that they heal with a well-marked and often characteristic scar. The frequent depigmentation in scars on black skins and the tendency of Africans to ready formation of keloids all add to the ease with which scars of old genital sores may be recognized.

Of course, there are many other causes for genital scars, tears in childbirth and infected scabies are two of the more common, but the typical regular, depressed, depigmented scar on the external genitals is commonly caused by chancre or chancroid only. Stokes and James (1949), discussing the diagnosis of BFP reactions, mention the importance of finding penile scars, but most other writers do not mention it. The finding of typical scars in an African with a positive STS reaction is considered a strong indication that the reaction is a true positive. It is also strong supporting evidence of a history of syphilis.

(iii) Parent of a Congenital Syphilitic.-Zellmann (1954) states that the diagnosis of congenital syphilis in a child is certain evidence of syphilis in the mother. In this series, where a child has been found to have congenital syphilis, there has been no hesitation in accepting the parents' positive Kahn result as a true positive.

(iv) Partner's Condition.-In the analysis of this series careful note was made of the clinical and serological state of husband and wife (or other sexual partner), when both partners were seen.

Where one partner was a case of primary or secondary syphilis, a positive Kahn test in the other partner was accepted without reservation as a true positive. 
Where one or both of the partners had a history of genital sores and/or genital scars, the finding of positive Kahn tests in both partners was taken as strong confirmatory evidence that both of them were true positives and not BFP reactions.

On the other hand, some doubt was felt about assuming, when neither partner had history, scars, or other evidence of syphilis, that because both partners had positive Kahn tests these were therefore true positives. From a village-to-village survey made in one area of the Eastern Province in 1950-51, it is known that 13.2 per cent. of adult Africans have positive or weak positive Kahn tests. On the evidence of this figure the chance of a man and woman who both had positive Kahn tests marrying is 1 in 57, which is small. However, since knowledge of the causes of BFP reactions in the tropics is so small, and since some of them may be due to dietary or environmental factors which would be likely to be common to both parties after marriage for any length of time, it is considered unjustifiable to assume that such positive Kahn tests are true positives.

Cases where one partner was persistently positive to the Kahn test and the other partner persistently negative presented a problem. On the face of it one would tend to regard such results as BFP reactions. There are, however, certain facets of African life which would predispose to such an occurrence.

(a) Marriage is often a fairly temporary arrangement. The African Affairs Annual Report for 1953 (Northern Rhodesia, 1954) shows that in the Eastern Province with 102,901 men, 2,407 divorce cases were heard before the native courts. That is to say, each year one man in every 43 obtains a divorce. It is thus probable that with a proportion of men the wife with whom he attended the clinic was not his wife at the time when he was in an infectious stage of syphilis. In fact, his positive Kahn test was a true positive and his present wife's negative a true negative. The practice of polygamy further complicates the issue.

(b) By custom, an African man will not have intercourse with his wife during the time she is breast-feeding a baby (up to 2 years). This taboo is less widely observed than previously but still holds great sway. There is ample time for the husband to acquire syphilis by extra-marital intercourse, and with minimal treatment to reach a non-infectious stage, during the time his wife is breast-feeding her baby. The husband would then give a true positive Kahn reaction, and his wife a true negative.

(c) A good many men from the rural areas go away to the towns to work. Most of them go for periods of 2 to 3 years, and their wives do not usually accompany them. The African Affairs Annual Report for 1953 shows that 38 per cent. of the men were away at work outside the province. These conditions are ideal for either husband or wife to acquire syphilis independently, and to reach a non-infectious stage by the time the husband returns from work.

Therefore, when only one partner gave a repeatedly positive Kahn test in the presence of a definite history and/or genital scars, such a result was still accepted as a probable true positive, even though the other partner gave a repeated negative Kahn test. When, however, a partner without history, genital scars, or other evidence of syphilis was found to have a positive Kahn reaction, the finding of a negative Kahn reaction in the other partner was taken as further evidence for classifying the first partner's positive as a probable BFP reaction.

(v) History of Repeated Abortions, Miscarriages, and Stillbirths.-Such a history is a well-recognized finding in syphilitic women. Kampmeier (1946) states that when syphilis remains untreated, pregnancy terminates in miscarriage or stillbirth in 24 per cent. of cases. Meyer (1951) found in a slum area of Paris that 11 per cent. of women having stillbirths and abortions had a positive Kahn test. Laird (1954) reported from Ceylon that in women who were sero-positive there was a higher proportion of foetal loss than in women who were sero-negative.

In this series there were 107 women who complained of repeated abortions, miscarriages, or stillbirths, without history, scars, or other evidence of syphilis. The Kahn test was positive in only fourteen (13 per cent.) of them. Such patients have therefore been classified as giving possible BFP reactions. Where, however, a positive Kahn reaction was found in a woman with a history and/or other evidence of syphilis, the history of repeated abortions, miscarriages, and stillbirths was taken as further confirmatory evidence for classifying the Kahn result as a probable true positive.

(vi) Other Factors.-Among the 1,889 patients who gave positive or weak positive Kahn tests and showed no signs of syphilis, there were three cases of chancroid, 21 of lymphogranuloma inguinale, three of granuloma venereum, and one of leprosy. In none of these could any evidence of syphilis, other than the positive Kahn test, be found. All of them have been classified as giving probable BFP reactions.

It is, of course, difficult to be absolutely certain in chancroid, lymphogranuloma inguinale, and granuloma venereum that a syphilitic infection does not co-exist. Several cases seen with a definite double infection (as shown by positive dark-ground), have been classified under the appropriate stage of syphilis.

In the cases of chancroid, lymphogranuloma inguinale, and granuloma venereum which have been classified as probable BFP reactions, not only was there no evidence of syphilis, but also the lesions healed without the use of antisyphilitic drugs, except in the case of granuloma venereum, where streptomycin was used.

In the whole series of 6,006 there was a total of thirteen cases of chancroid (without evidence of concurrent syphilis). Of these, three ( 23 per cent.) gave positive Kahn tests. Stokes and others (1944b) state that the occurrence of BFP reactions in chancroid is denied by some, but quote another series of 24 patients in which five gave BFP reactions. Moore and Mohr (1952a) give the incidence of BFP reactions in chancroid as 5 per cent.

Of 36 cases of lymphogranuloma inguinale (without evidence of concurrent syphilis), 21 (58 per cent.) gave positive Kahn reactions. Stokes and others (1944b) quote 6 to 36 per cent. as the estimated incidence of BFP reactions in this condition. Moore and Mohr 
(1952a) give 20 per cent. Simpson (1954), in a series of 200 cases of lymphogranuloma inguinale among British troops in India, found twelve who had positive STS reactions, of whom six subsequently proved to have syphilis, giving the incidence of BFP reactions in his series as 3 par cent.

Of the four cases of granuloma venereum in the series, three gave positive $\mathrm{Kahn}$ tests. It is extremely difficult to exclude the possibility of previous syphilis in this condition, and no conclusions can be drawn from such small numbers.

\section{Results of Assessment}

An analysis of the 1,889 patients who gave positive or weak positive Kahn results without any clinical manifestations of active syphilis is given in Table 11. Without the use of the TPI test or of cerebrospinal fluid examination it is impossible to be entirely accurate in the assessment of these cases. For this reason the words "possible" and "probable" have been used in conjunction with the final assessment. Using the indications enumerated and discussed above, patients have been assessed as follows :

(i) Probable True Positive Results.-Patients placed in this category had two or more indications of syphilis, besides their serological result. The exceptions to this rule were 33 patients in whom the only evidence was that their sexual partner had early infectious syphilis,

TABLE II

ANALYSIS OF 1,889 PATIENTS WHO GAVE REPEATEDLY POSITIVE OR WEAK POSITIVE KAHN TESTS, AND HAD NO CLINICAL MANIFESTATIONS OF ACTIVE SYPHILIS

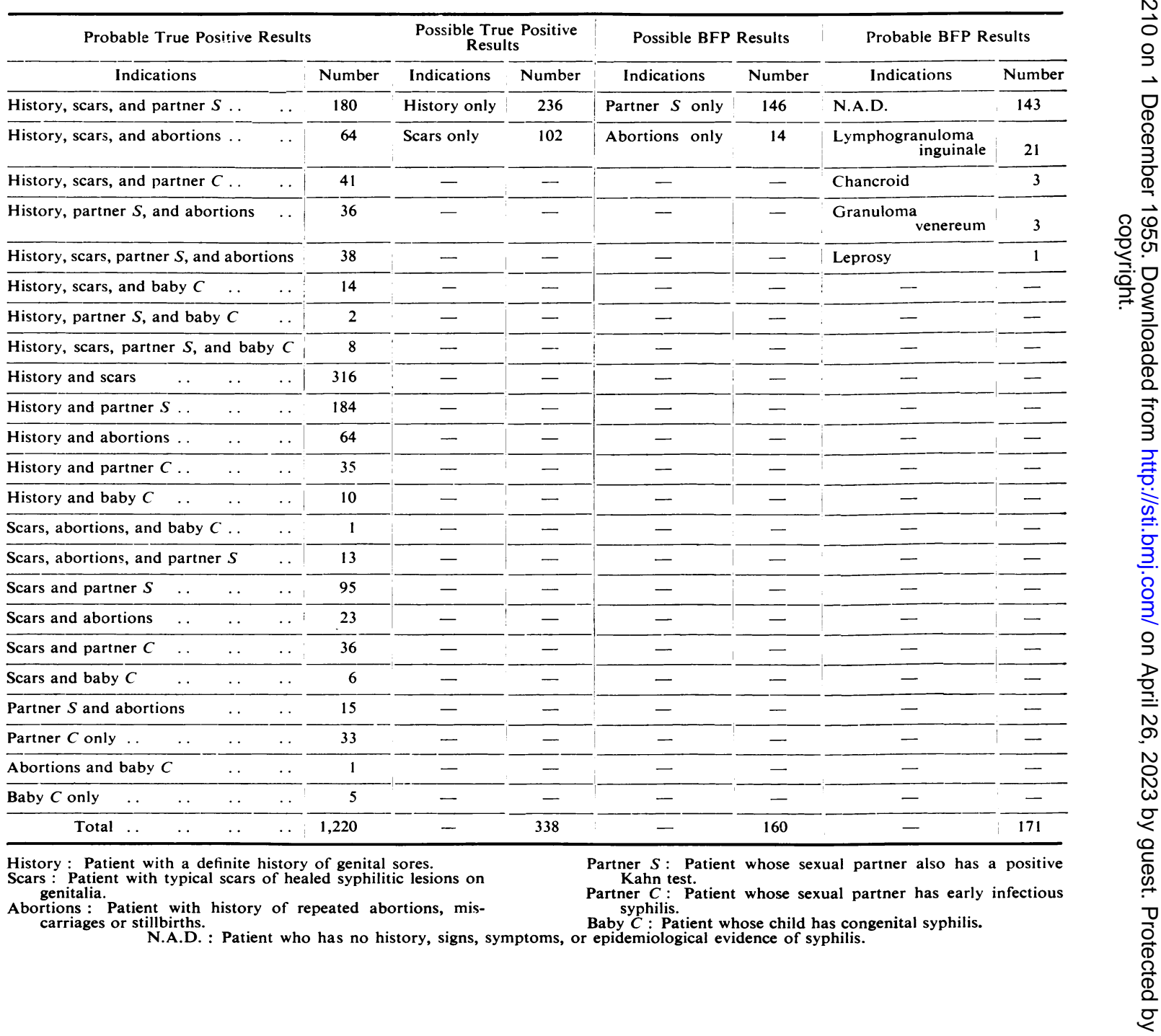


and five women who were the mothers of babies with congenital syphilis. It is considered that patients in this group gave very strong evidence for accepting their serological positive result at face value. It is believed that in all, or very nearly all, of them the positive Kahn reaction was a true and not a false positive reaction.

A total of 1,220 patients were assessed as probable true positive. Some surprise may be felt at the large number of patients who fall into this category. It must, however, be remembered that, for years now, rural dispensaries have been treating cases of syphilis with injections of bismuth. A scrutiny of the records from several rural dispensaries shows that only about half the patients attended for more than two bismuth injections. It is not therefore surprising that there are a large number of latent syphilitics in the area.

(ii) Possible True Positive Results.-The only patients placed in this category were those in whom the only evidence to support the positive Kahn result was either a history of genital sores only, or the presence of typical genital scars only. It is accepted that in a small proportion of cases the history might refer to a non-syphilitic lesion, or the scars might result from such a lesion. However, it seems justifiable to assume that, in the majority of cases, the original lesion was syphilitic and that the Kahn result obtained from such patients was in fact a true positive result in most of them. A total of 338 patients were assessed as possible true positive.

(iii) Possible BFP Reactions.-To support their positive Kahn result, the patients placed in this category had only a history of repeated abortions, miscarriages, and stillbirths, or else only the fact that their sexual partner also gave a positive Kahn result. The reasons for believing that the majority of the results obtained from these patients were in fact BFP reactions have already been outlined above. A total of 160 patients have been assessed as possible biologic false positive.

(iv) Probable BFP Results.-Patients with lymphogranuloma inguinale, chancroid, granuloma venereum, and leprosy have been included in this category. In addition 143 patients ( 53 men and ninety women) have been included in whom no history, scars, signs, symptoms, or epidemiological evidence of syphilis could be found to support their positive Kahn results. These patients are shown as "N.A.D." in Table II and subsequently. There seems every reason to believe that the positive Kahn results obtained in all or nearly all of these patients were BFP reactions, and 171 patients have been assessed as probable biologic false positive.

From the whole group of 6,006 successive adult African patients attending at the various V.D. clinics, 2.8 per cent. were considered to give probable BFP results, and a further $2 \cdot 7$ per cent. were considered to give possible BFP results using the Kahn test, making a total of 5.5 per cent. Probably the true incidence of BFP reactions for the whole group lies somewhere between 2.8 and 5.5 per cent.

Taking the group of 1,889 patients who were found to have a repeatedly positive Kahn test in the absence of manifestations of active syphilis (i.e., potential latent syphilis), in 64.6 per cent. the Kahn result was thought to be almost certainly a true positive (probable true positive) and in a further 17.9 per cent. it was considered that the majority were true positive (possible true positive). In 9 per cent. the positive Kahn result was thought to be almost certainly a BFP reaction (probable BFP) and in a further 8.5 per cent. it was considered that the majority were BFP reactions (possible BFP), making a total of 17.5 per cent. Probably the true incidence of BFP reactions among the 1,889 potential latent syphilitics is somewhere between 9 and $17 \cdot 5$ per cent.

It is interesting to observe the relative incidence of positive and weak positive tests among the patients classified as probable BFP. Table III shows that BFP results were notably more common among the weak positives. This is even clearer when the whole series is considered. Of a total of 1,702 positives, 68 (4 per cent.) were considered to be probable BFP, whereas of 1,239 weak positives 104 (8.4 per cent.) were considered to be probable BFP. That is to say, in this series, a weak positive Kahn result was twice as likely as a positive Kahn result to be a BFP. There are, however, enough probable BFP reactions among the positive results to make any generalization impracticable.

The incidence of BFP reactions among the 1,889 patients with "potential latent syphilis" is well below that found in many published series. The figure of 9 to 17.5 per cent. found in this series is well below the 40 per cent. suggested by Stokes and James (1949) as liable to be found in a series of routine positives. The explanation of the low percentage of BFP reactions among the positive results is probably to be found in Wilkinson's (1954) observation that, where the incidence of syphilis is high, the incidence of latent syphilis will be high, and the percentage of BFP reactions in a series of positives will be correspondingly low.

TABLE III

RELATIVE INCIDENCE OF POSITIVE TO WEAK-POSITIVE RESULTS AMONG 171 PROBABLE BFP REACTIONS

\begin{tabular}{|c|c|c|c|c|}
\hline \multicolumn{2}{|c|}{$\begin{array}{l}\text { Clinical } \\
\text { Findings }\end{array}$} & \multirow{2}{*}{$\frac{\text { Positive }}{62}$} & \multirow{2}{*}{$\frac{\begin{array}{c}\text { Weak } \\
\text { Positive }\end{array}}{81}$} & \multirow{2}{*}{$\frac{\text { Total }}{143}$} \\
\hline N.A.D. & . & & & \\
\hline Lymphogran & $\begin{array}{l}\text { nuloma } \\
\text { inguinale }\end{array}$ & 5 & 16 & 21 \\
\hline Chancroid & $\cdots$ & - & 3 & 3 \\
\hline Granuloma & venereum & - & 3 & 3 \\
\hline Leprosy & . & - & 1 & 1 \\
\hline Total & . & $\begin{array}{c}67 \\
(39 \cdot 2 \text { per cen }\end{array}$ & $\begin{array}{c}104 \\
(60 \cdot 8 \text { per cent. })\end{array}$ & 171 \\
\hline
\end{tabular}


The incidence of syphilis in this area is certainly high by most standards.

\section{Discussion}

It is apparent that the incidence of BFP reactions in the total series (between $2 \cdot 8$ and $5 \cdot 5$ per cent.) is considerably higher than any reported from temperate areas. In the published reports, discussed above, the quoted incidence of BFP reactions among clinic patients varied from 0.01 to 1.16 per cent. Nevertheless, it seems certain that the positive serological reactions in these African patients can in the majority of instances ( 94.5 per cent. or more) be equated with a syphilitic infection. The finding of a positive serological test for syphilis in an African is an indication that the same careful search for clinical, laboratory, anamnestic, and epidemiological evidence of syphilis should be made as in a European patient. The practice of disregarding serological positive results without such a search in Africans, in the absence of overt signs of syphilis, is doomed to disaster.

There remains the problem why the incidence of BFP reactions in the whole series is higher than that reported from temperate climates. Malaria and leprosy are common in this area and are widely recognized as causes of BFP reactions. These two factors have been further investigated.

\section{Malaria AND BFP Reactions}

It has been generally accepted that malaria is a cause of BFP reactions. Beerman (1945) describes it as one of the worst offenders. It is of course realized that malaria can cause a syphilitic infection which has reached sero-negativity to become sero-positive again. Taussig and Orgel (1937) describe one such case. Babin and Dulaney (1945) observed that the Wassermann titre rose in 82 per cent. of 22 syphilitic patients inoculated with malaria. Considerable caution is needed, however, in accepting a positive STS after malaria as necessarily a BFP reaction, and Beerman (1945) advises that, if positivity persists by any test for more than 6 weeks in the absence of continued malaria, suspicion of syphilis should be aroused. Syphilis and malaria do of course often co-exist. Wheeler and others (1954) who performed TPI tests on six patients with positive STS results and malaria, found a positive TPI in one of them.

Reports on the incidence of BFP reactions in malaria vary widely. Moore and Mohr (1952a), using repeated tests, give the incidence as 100 per cent. at some stage. Kolmer and Lynch (1953) and Stokes and others (1944b) quote a similar result, whereas Hudson (1951) reporting on bejel in Iraq could find no difference in the serological results, whether his specimens came from a malarious area or not. Kahn (1950e, 1954) described, with his universal serological reaction, an intensification of the normal reaction in malaria (as opposed to a characteristic pattern), which might or might not be sufficient to bring it into the sero-diagnostic range. He observed that this did not occur at the time of the attack, but some 2 weeks later.

Published reports fall into two categories: those based on results from experimental inoculation of malaria, and those from patients with naturally acquired malaria. They also vary as to the type of causative plasmodium.

(a) Experimental Malaria.-Most reports on BFP reactions after inoculation of malaria deal with tertian (Plasmodium vivax) infections. Possibly the scarcity of reports on infections with Plasmodium falciparum may in part be due to a natural unwillingness to inoculate with a form of infection that bears the name malignant malaria. Rein and Kent (1947) studied the incidence of BFP reactions during experimental studies concerned with the chemotherapy of malaria in volunteers (free of all signs, symptoms, history, etc. of syphilis) in the United States Penitentiary, Atlanta. Specimens for STS were obtained from each volunteer before inoculation with Plasmodium vivax, daily during the attack, two or three times weekly after the attack, and then at weekly intervals up to 18 months. Tests undertaken included the Standard Kahn, Hinton, Kline, Mazzini, and Boerner-Jones. A total of ninety volunteers took part in the experiment, and 63.3 per cent. gave a BFP reaction at some time during the course of the disease. They were characteristically of low titre, appearing on an average of 8.3 days after the onset of parasitaemia (limits 0 to 30 days) and persisting for 2 to 98 days. Kent, Culwell, Coatney, and Cooper (1948), continuing this study further, reported a greater number of BFP reactions with flocculation than with complementfixation tests, and with lipoidal than with cardiolipin antigens. They observed BFP reactions persisting for up to 181 days when successive malarial relapses extended the sero-positivity due to an earlier stimulating attack.

Kitchen, Webb, and Kupper (1939) reported results on 25 patients in whom malaria was induced for functional psychoses. Specimens of serum were obtained before inoculation with malaria and then at semi-weekly intervals until they were negative. Tests used were the Wassermann and the Kahn. All patients produced a BFP reaction at some stage. The percentage of positive reactions was highest 15 to 21 days after the last paroxysm, and the duration of positivity exceeded 3 weeks in 60 per cent. and exceeded 4 weeks in 48 per cent. Most of their patients were inoculated with Plasmodium vivax infections, but some with Plasmodium falciparum, and they noted a tendency for the latter to produce fewer positive results. Burney, Mays, and Iskrant (1942), also working with induced Plasmodium vivax malaria in nonsyphilitic psychotics, came to substantially the same conclusions as Kitchen and his co-workers.

Olansky and others (1953) reported on 130 nonsyphilitic volunteers from a U.S. Penitentiary inoculated with $P$. vivax malaria. The first specimens for STS were taken immediately before inoculation. Daily blood smears were done, and a second blood test was taken 10 days after maximum parasitaemia had developed. They did a battery of tests on both specimens, and found the following results in the post-inoculation specimens : 
(i) Kolmer : 51.0 per cent. positive,

(ii) Kolmer Cardiolipin : $18 \cdot 3$ per cent. positive,

(iii) Kline Standard : $22 \cdot 3$ per cent. positive,

(iv) Kahn Standard : $82 \cdot 3$ per cent. positive,

(v) VDRL Slide Test : 3.8 per cent. positive.

Thus the lowest incidence of BFP reactions was with cardiolipin antigens, and they further noted that using lipoidal antigen in quantitative tests quite a number gave high titre results, whereas, using cardiolipin antigen, titres were much lower. They also state that Plasmodium falciparum infections are less likely to cause BFP reactions than Plasmodium vivax infections.

(b) Naturally Acquired Malaria.-Singh (1947) performed STS on patients with malaria in hospital in India. Tests used were the Wassermann and the Kahn, and he found positive results in 38.6 per cent. Since 11.3 per cent. of the non-malaria patients in the hospital had positive STS results, he gave the incidence of BFP reactions in malaria as $27 \cdot 3$ per cent. He could find no relation between the occurrence of BFP reactions and either the patient's temperature at the time of taking the specimens, or the type of the malaria parasite. Wilson and Levin (1936) studied BFP reactions among malaria patients in South Carolina. Excluding all patients with any suggestion of syphilis, they found that 6.3 per cent. of 263 patients gave BFP reactions. About one-third of them were Plasmodium falciparum infections, but they gave no comparison between the incidence of BFP reactions in the different types of infection. They also reported one case in which malaria apparently caused a BFP reaction in the cerebrospinal fluid. Rein and Elsberg (1944) reported a small series of malarial patients (non-syphilitic and sero-negative before the attack) and found 44 per cent. developed a BFP reaction between the seventh and fourteenth day following the first paroxysm. Robinson and McKinney (1945) studied 100 non-syphilitic soldiers who had recently been transferred from a malarial area, and who had Plasmodium vivax in the blood smear. They did blood Kahn tests on them and examined their cerebrospinal fluids (Kahn test, Pandy test, and cell count). The results of the cerebrospinal fluids were all normal, except that in two of them the Pandy test was reported as "a trace". Of the Kahn tests done on their bloods, 33 per cent. were positive and a further 11 per cent. doubtful. On weekly testing they found that 83.8 per cent. of the positives and 70 per cent. of the doubtfuls were negative within 4 weeks, and all cases were negative after 11 weeks.

Manson-Bahr (1945a) states " about 28 per cent. of malarial bloods in the acute stages of malaria, when parasites are plentiful in the peripheral blood, give a positive Wassermann reaction". He quotes the results of Wassermann reactions performed on 246 malarial patients as follows :

(i) Plasmodium falciparum, $8 \cdot 2$ per cent. positive,

(ii) Plasmodium vivax, $11 \cdot 8$ per cent. positive,

(iii) Plasmodium malariae, 20.5 per cent. positive.

Taussig and Orgel (1937) reported the results of Kahn tests performed on 154 non-syphilitic patients in St. Louis. Nearly all of them were Plasmodium vivax infections.
They found that 21 per cent. gave positive Kahn tests, and observed that, in those whom they followed up, the Kahn test became negative within 15 days of quinine therapy. Andujar and others (1948) found two patients with positive Kahn tests and five doubtful Kahn tests out of 24 cases of malaria (chiefly Plasmodium vivax), giving a total of 29 per cent. Cumming, Hazen, Sanford, Senear, Simpson, and Vonderlehr (1935) reported that, of a total of 35 malaria patients, four (8.6 per cent.) gave positive Kahn results. However, when they used a battery of tests, the incidence rose to 20.6 per cent. Willcox (1949) reported the results of Kahn tests done on 112 Africans with malaria in Southern Rhodesia. He did not mention the type of infection, but the vast majority would almost certainly be Plasmodium falciparum. He found 9.8 per cent. Kahn positive and a further $15 \cdot 2$ per cent. Kahn doubtful (total 25 per cent.). Nelson (1947) performed a battery of STS on 100 European Service personnel with acute Plasmodium falciparum malaria on the Gold Coast. He did STS within 24 hours of the onset of parasitaemia, and again on the tenth day, and found an incidence of positive results of 3 per cent. (Ide test, 2 per cent.; Meinicke test, 4 per cent. ; and Kahn test, 3 per cent.).

Thus, in the reports quoted above, the incidence of BFP reactions in induced malaria varied between 100 and 3.8 per cent. depending on the tests used, and in naturally acquired malaria between 44 and 2 per cent.

\section{Present Investigation}

In an attempt to elucidate the part played by malaria in causing BFP reactions in the Eastern Province of Northern Rhodesia, Kahn tests were performed on a series of African patients with positive blood slides for malaria at the African Hospital, Fort Jameson. A total of 137 patients were so examined, and 38 (27.7 per cent.) were found to give positive or weak positive Kahn results. It was not found possible to examine these patients for syphilis since usually, by the time the Kahn test result was available, the patient had had his antimalarial treatment and had ceased to attend the African Hospital. The only criterion for inclusion in this series was that the patient should have a malarial parasitaemia (Plasmodium falciparum) in all cases, and that the laboratory assistant could find time from his other duties to track down the patient, after he had read the blood smear, and take the blood sample for Kahn testing. A brief note however was made on each patient, giving his approximate age, and whether or not he had fever at the time of taking the blood specimen for the Kahn test.

The majority of the positive patients ( 79 per cent.) were in the "weak-positive" range (Table IV, opposite). It will be seen that the incidence of positive results is much higher among children than among adults. Of 97 adults, 23 (23.7 per cent.) gave a positive Kahn result, whereas of the forty children, fifteen ( 37.5 per cent.) gave positive Kahn results. There appears to be no relation between the occurrence of positive Kahn results and the presence or absence of fever at the time the specimen was taken.

Stokes and others (1946) in Philadelphia were able to show a degree of parallelism between the monthly 
incidence of BFP reactions and the monthly incidence of pneumonia. In an attempt to assess the importance of malaria as a cause of BFP reactions further analysis of the 6,006 patients, described earlier, has been undertaken. The percentage of patients classified as " N.A.D." (no history, signs, symptoms, or epidemiological evidence of syphilis, but showing a repzatedly positive Kahn test) has been worked out for each month. An indication of the monthly variation in the incidence of malaria has been obtained from the number of patients found

TABLE IV

KAHN RESULTS IN PATIENTS WITH MALARIA

\begin{tabular}{|c|c|c|c|c|c|}
\hline \multirow{2}{*}{\multicolumn{2}{|c|}{ Kahn Result }} & \multicolumn{2}{|c|}{ Adults } & \multicolumn{2}{|c|}{ Children } \\
\hline & & Fever & No Fever & Fever & No Fever \\
\hline Positive $\quad$. & $\ldots$ & 3 & 1 & 4 & - \\
\hline Weak positive & 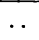 & 14 & 5 & 11 & - \\
\hline Negative ... & $\ldots$ & 58 & 16 & 22 & 3 \\
\hline Total & $\ldots$ & 75 & 22 & 37 & 3 \\
\hline
\end{tabular}

to have positive malaria blood smears at the African Hospital, Fort Jameson, for each month during 1954. There is close parallelism between the monthly variations of the incidence of BFP reactions and of malaria throughout the year (see Figure below).

\section{Discussion}

From the results described above it is apparent that a greater percentage of positive Kahn results occurred in Africans with malaria than in the general population. The village-to-village survey carried out in 1950-51 showed that 13.2 per cent. of the adult population had positive Kahn tests,

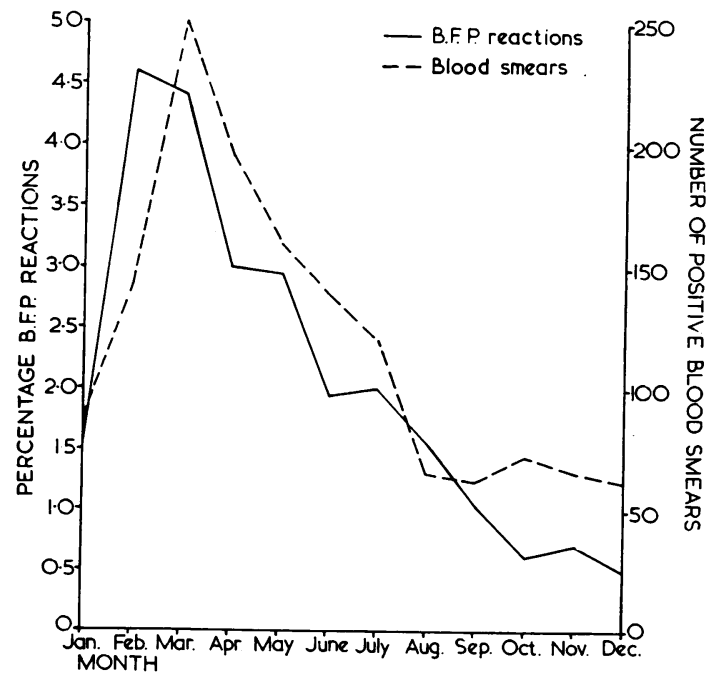

FIGURE.-Monthly percentage incidence of BFP reactions and monthly number of positive blood smears for malaria for 1954 . whereas among the adults with malaria $23 \cdot 7$ per cent. had positive Kahn tests-an increase of 10.5 per cent. It is more than likely that, had serial testing been carried out on the patients, a higher percentage of positives would have been found, but it seems unlikely that this would have reached the high percentage described in experimentally inoculated malaria.

There is one obvious difference between the healthy American prison inmate inoculated with malaria, and the African in his village bitten by an infected mosquito ; that is, for the American it is probably his first attack of malaria, whereas for the African it is only the latest in a long series. Rein and Kent (1947), reporting their study on penitentiary inmates inoculated with malaria, noted that, "the incidence of false positive reactions appears highest in early primary malaria, somewhat lower in delayed primary attacks, and lowest in relapses". This would seem to indicate that the body responds to the repeated assaults of malaria by producing less and less reagin. Repeated attacks, such as are the lot of the African living in an area of endemic malaria, would therefore tend to produce relatively few BFP reactions. Possibly racial and acquired immunity to malaria would also play some part in this mechanism.

Further support to this supposition is given by the high incidence of positive Kahn tests found among children with malaria. Admittedly the numbers are small, but the finding of a positivity rate among the children of 37.5 per cent. as compared with 23.7 per cent. among adults requires some explanation. It can be assumed that the children would, generally, have had far fewer attacks of malaria than the adults, and would therefore be more likely to respond to an attack of malaria by producing a BFP reaction. Scrutiny of the Kahn results among the malarial children shows a tendency for more positives to occur among the younger age groups. This is in keeping with the report by Smith (1950) from an area of Northern Rhodesia that over the age of 1 year the spleen rate (on which he judged the incidence of malaria) tended to diminish with rising age. Laurie (1954), working on Ukara Island in Lake Victoria, found in a random group, from whom blood films were examined for malaria, that the incidence of positive films fell as age increased. He also found that, while the adult population gave 14 to 16 per cent. positive Kahn tests, 13 per cent. of the children also gave positive results, possibly caused by malaria.

It is, of course, possible that the positive Kahn tests found among children are due to a form of endemic syphilis or to congenital syphilis. However, 
since congenital syphilis, though commonly seen in Africans in the first year or two of life, is rarely encountered later, and since no cases suggestive of endemic syphilis have been seen, this possibility seems remote. Furthermore, Guthe and Reynolds (1951), reporting on endemic syphilis in Bosnia, noted that the sero-positivity rate rose from 0.6 per cent. in the 0 to 5 years age group to 13.4 per cent. in the 16 to 18 years age group, whereas in the series reported here the highest incidence of sero-positivity was in the younger children.

That malaria is a cause of BFP reactions in the Eastern Province of Northern Rhodesia cannot be doubted. The higher percentage of positive Kahn results among adults with malaria as compared with the general adult population, and the parallelism observed between the monthly incidence of malaria and BFP reactions, are both indications that malaria plays a definite part in the occurrence of BFP reactions. The only surprising factor is that, in an area where the population is frequently subjected to the assaults of malaria from birth, the BFP reactions are not very much higher $(2 \cdot 8$ to $5 \cdot 5$ per cent. in the series of 6,006 described above). The well recognized tendency for Plasmodium falciparum infections to cause fewer BFP reactions than other types may explain in part the low figures. The supposition that the repeated attacks of malaria may have a diminishing effect in evoking BFP reactions would further explain the findings.

\section{LEPROSY AND BFP REACTIONS}

From the early days of serological tests for syphilis, leprosy has been recognized as causing false positive reactions. Badger (1931), in a review of the literature, noted very diverse opinions as to the incidence of BFP reactions in leprosy. Beerman (1945), in a more recent review, also noted similar wide variation in the reported incidence, but found that the trend was generally towards a high percentage. Manson-Bahr (1945b) points out that leprosy and syphilis often co-exist. He states that,

In mild early cases of leprosy, positive [Wassermann] reactions denote coincident spirochaetal infection, but in advanced cutaneous and neural cases, especially those subject to lepra fever, a positive reaction does not necessarily always indicate a syphilitic infection.

Moore and Mohr (1952a) state that the BFP reaction associated with leprosy is of the "chronic" type, wherein positivity persists for months or years. Kahn (1950b, 1954) described, with his universal serological reaction, a typical serological pattern in lepromatous leprosy, which tended to move out of the "diagnostic range" with improvement in the leprosy. He mentions, however, that this typical pattern is often absent, and postulates that it may often be masked by the effect of intercurrent diseases so often found in leprosy. He also states that sero-diagnostic tests for syphilis are commonly negative in tuberculoid and non-characteristic forms of leprosy. Davis (1944) suggested that the increasing percentage of STS-positivity among lepers may be attributed to the increasing sensitivity of modern STS.

Badger (1931), who reported on 207 lepers in Honolulu, found 20.2 per cent. positive with Wassermann and 27.5 per cent. with Kahn. One or both tests were positive in 28.9 per cent. When the tests were repeated one to three times at intervals, the percentage positive rose to 34.8. The incidence of sero-positivity in lepers was three times as great as among the general population. Positive results were found more often under than over 20 years of age. He also noted that a marked clinical improvement was often accompanied by a return to sero-negativity, that clinical fluctuation was often accompanied by serological fluctuation, and that leprous reactions were often accompanied by a change from sero-negative to sero-positive. Correlation between clinical state and strength of quantitative Kahn result was also noted. He found no difference in incidence of sero-positivity between dermal and neural types.

In a review of serological techniques in the United States, Cumming and others (1935) reported performing STS on fifty cases of leprosy, and found thirty were positive and one doubtful with the Kahn test (62 per cent.). Positive results obtained with different tests on these fifty lepers varied between 42 and 76 per cent. Rein and Elsberg (1944) found 85 per cent. among eighty lepers positive to a battery of STS. Kolmer and Lynch (1953) state that in leprosy single tests may only give 15 to 20 per cent. false positive reactions, whereas incidence based on repeated tests may be 60 per cent. or higher. Moore and Mohr (1952a) give the incidence of BFP reactions in leprosy as 60 per cent. Singh (1949), reporting on Kahn tests done on 64 non-syphilitic lepers in India, found that 26.5 per cent. gave strong positive and a further 15.6 per cent. gave weak positive results (42.1 per cent.). In lepromatous cases 35.4 per cent. gave strong positive and 22.2 per cent. weak positive results, whereas in neural types $5 \cdot 2$ per cent. gave strong positives and there were no weak positives. He also observed, using quantitative tests, that leprosy caused BFP reactions of higher titre than he usually found from other causes (malaria, post-vaccination, etc.).

Nelson (1952) examined seventy apparently nonsyphilitic lepers of whom 57 (80.1 per cent.) gave positive results with various STS. Of the 57 showing positive results, eleven gave a positive TPI test, thus making the incidence of BFP reactions in leprosy 66.6 per cent. Portnoy, Ramiro Galvez, and Cutler (1952) examined 51 non-syphilitic lepers in Guatemala with a battery of STS and found the incidence of BFP reactions to be :

(i) Kahn : 54.9 per cent.,

(ii) Kolmer : $22 \cdot 7$ per cent.,

(iii) Kolmer Cardiolipin : 30.9 per cent.,

(iv) VDRL : $29 \cdot 2$ per cent.,

(v) Mazzini : 58.8 per cent.

They found cutaneous leprosy gave a higher percentage of positives than neural leprosy. Willcox (1949) performed the Kahn test on 829 lepers in Southern Rhodesia and found 16.0 per cent. positive and 11.8 per cent. doubtful (total 27.8 per cent.). Stokes and others 
(1944b) quote the incidence of BFP reactions in leprosy as 60 to 80 per cent.

Thus, from the reports mentioned above, the published incidence of BFP reactions in leprosy varies between 20 and 85 per cent.

\section{Present Investigations}

Kahn tests were performed on 477 leper patients in two leper colonies (Nsadzu Mission Leper Colony and Mwami Mission Leper Colony). Of these, 21 (4.4 per cent.) gave positive results, and a further 67 (14 per cent.) gave weak positive results (total 18.4 per cent.). Patients with syphilis were excluded as far as possible.

It was noticed that positive Kahn results were much commoner among the female lepers than among the males. Of 243 female lepers, $15(6 \cdot 1$ per cent.) gave positive Kahn results and a further 45 (18.5 per cent.) gave weak positives, giving a total of 24.6 per cent. Of the 234 male lepers, however, only six ( $2 \cdot 6$ per cent.) gave positive Kahn results, and 22 ( 9.4 per cent.) weak positive ones, making a total of only 12 per cent.

In 408 of the leper patients the predominant type of leprosy at the time of the Kahn test was recorded. In many cases a mixed type existed, e.g., predominantly lepromatous but with a polyneuritic element. Positive results were commoner in lepromatous cases than in polyneuritic, and least common in tuberculoid ones (Table V).

\section{TABLE V}

TYPE OF LEPROSY AND KAHN POSITIVITY

\begin{tabular}{|c|c|c|c|c|}
\hline $\begin{array}{c}\text { Type of } \\
\text { Case }\end{array}$ & & $\begin{array}{c}\text { Total } \\
\text { Number } \\
\text { of Cases }\end{array}$ & $\begin{array}{c}\text { Number } \\
\text { Kahn } \\
\text { Positive }\end{array}$ & $\begin{array}{c}\text { Percentage } \\
\text { Kahn } \\
\text { Positive }\end{array}$ \\
\hline Lepromatous & . & 250 & 53 & $21 \cdot 2$ \\
\hline Polyneuritic & - & 86 & 10 & $14 \cdot 8$ \\
\hline Tuberculoid & $\ldots$ & 69 & 6 & $8 \cdot 1$ \\
\hline Intermediate & $\ldots$ & 3 & - & - \\
\hline Total & $\ldots$ & 408 & 69 & - \\
\hline
\end{tabular}

In 210 patients the bacteriological status of the leprosy when the Kahn test was performed was recorded. No correlation between the bacteriological status and the Kahn result was observed. Of 69 patients who were bacteriologically positive, eleven (15.9 per cent.) were Kahn positive, and of 141 who were bacteriologically negative, 21 (14.9 per cent.) were Kahn positive.

Patients in this series had been under treatment from 1 month to 25 years. In 233 of the patients the length of treatment was compared with the percentage giving positive Kahn results (Table VI). No correlation could be found between these two factors. The impression was gained that positive Kahn results tended to go hand-in-hand with the activity of leprosy. This is difficult to show statistically. However, 234 cases were analysed into first, second, and third stage according to the activity of leprosy at the time of performing the Kahn test. Of 68 cases in the third stage and 67 in the second stage, $19 \cdot 1$ per cent. and 25.4 per cent. gave positive Kahn results respectively, whereas of 99 in the first stage, only three ( 3 per cent.) were positive.
TABLE VI

LENGTH OF LEPROSY TREATMENT AND KAHN RESULT

\begin{tabular}{|c|c|c|c|c|c|}
\hline $\begin{array}{l}\text { Kahn } \\
\text { Test }\end{array}$ & $\begin{array}{c}0-3 \\
\text { Months }\end{array}$ & $\begin{array}{c}3-6 \\
\text { Months }\end{array}$ & $\begin{array}{c}6 \\
\text { Months- } \\
1 \text { Year }\end{array}$ & $\begin{array}{c}1-3 \\
\text { Years }\end{array}$ & $\begin{array}{l}\text { Over } 3 \\
\text { Years }\end{array}$ \\
\hline Negative $\quad$. & 37 & 25 & 45 & 35 & 49 \\
\hline Positive & 7 & 7 & 8 & 10 & 10 \\
\hline Positive $\% \ldots$ & 15.9 & 21.9 & $15 \cdot 1$ & $22 \cdot 2$ & 16.9 \\
\hline
\end{tabular}

Discussion

The incidence of positive Kahn results among the leper patients here recorded (18.4 per cent.) is lower than that in most reported series. This may possibly be due to a preponderance of cases in whom the activity of the disease was low when the tests were taken. The published reports quoted above give no indication of the activity of the disease when the STS were performed. If, as seems probable, seropositivity is to some extent related to the activity of the leprosy, then the number of BFP reactions in any given series will vary directly with the number of patients in the more active stages of the disease.

In the discussion of BFP reactions in malaria, it was suggested that the percentage incidence could be found by subtracting the percentage incidence of positive Kahn results in the adult population of the Eastern Province of Northern Rhodesia from the percentage incidence of positive Kahn results in adults with malaria. A similar method of estimating the incidence of BFP reactions in leprosy would not however be valid, for the following reasons;

(i) While the majority of patients in the two leper colonies come from the Eastern Province, a large minority come from other provinces, or from Nyasaland or Portugese East Africa, areas where the prevalence of sero-positivity may be, and in some cases is known to be, markedly different from that in the Eastern Province.

(ii) The figure available for the incidence of seropositivity in the Eastern Province applies only to adults, whereas the figures obtained from the leper colonies include quite a number of children.

(iii) The inmates of the two leper colonies receive a diet which is better than that enjoyed by the average African feeding himself. Many of the lepers examined have been inmates of the colonies for considerable periods. If, as has been suggested, dietary variations play some part in causing BFP reactions, then the better diet in a leper colony might well play some part in increasing or decreasing the incidence of BFP reactions.

The finding that positive Kahn results were twice as common in female as in male lepers was noted with interest. Scrutiny of the individual case records failed to reveal a higher proportion of female lepers in the more active stages. Badger (1931) made a similar observation.

The finding that lepromatous leprosy is more 
prone than the other types to be associated with positive STS results has been widely mentioned in published reports. Similarly, the failure to correlate bacteriological status or length of treatment of leprosy with the occurrence of BFP reactions has been previously reported by Badger (1931) and by Portnoy and others (1952) respectively.

While there seems little doubt that leprosy is a cause of BFP reactions in individual cases, its effect in the aggregate is probably small. The incidence of leprosy in the Eastern Province is estimated as 12.6 per thousand (Health Department Annual Report for 1950, Northern Rhodesia, 1951). From the series reported above it may be assumed that 18.4 per cent. of lepers will give a false positive result to STS. It follows that the incidence of BFP reactions due to leprosy will be approximately 0.24 per cent. of the total population in this area.

\section{SUMMARY}

The literature on false positive reactions to the standard serological tests for syphilis is reviewed, with special reference to their occurrence in the tropics, and their association with leprosy and malaria. Of the various laboratory procedures for the differentiation of true and false positive results, only the treponemal immobilization test is of proven value, and this is not, as yet, a practical proposition in most parts of Africa.

In an attempt to assess the incidence of these false positive reactions, the Kahn results obtained from 6,797 successive adult African patients attending at V.D. clinics in the Eastern Province of Northern Rhodesia have been studied. In 791, recorded details were insufficient to make a final assessment. Of the remaining 6,006 patients, there were 1,889 in whom the Kahn test was persistently positive without overt signs of active syphilis.

These 1,889 patients were further assessed in an attempt to decide whether their Kahn results were true or false positive reactions. The factors considered in making the assessment are fully described, together with their limitations. It is realized that the figures given for the final assessment are only approximate. It is estimated that, of the 1,889 potential latent syphilitics, somewhere between 9 and $\mathbf{1 7 . 5}$ per cent. gave false positive results. This gives an estimated incidence for the whole group $(6,006)$ of somewhere between $2 \cdot 8$ and $5 \cdot 5$ per cent.

Kahn tests were performed on 137 African patients with malarial parasites in the blood and 38 (27.7 per cent.) were found to give positive or weak positive results. The incidence of positive Kahn results among the children with malaria was higher than among the adults. The theory is advanced that, in areas of endemic malaria, repeated attacks of malaria starting in infancy may have a diminishing effect in producing false positive results, so that by the time adult life is reached malaria will play only a small part in producing false positives. A suggestive degree of parallelism was observed between the monthly incidence of false positive results and that of malaria throughout the year.

A total of 477 lepers were submitted to the Kahn test, and 18.4 per cent. were found to give positive or weak positive results. Positive results were twice as common in female as in male lepers. A higher percentage of positive results was found among patients with lepromatous than with other types of leprosy. The activity of the disease appeared to be an important factor in the occurrence of positive results. While it seems certain that leprosy is a cause of false positive results in individual cases, the known incidence of leprosy in the population at large in this area and the relatively small number of lepers showing positive Kahn results at any one time suggest that, in the aggregate, the effect of leprosy will be small.

\section{Conclusion}

It seems certain that in the majority of cases recorded here, the positive serological response could be equated with a syphilitic infection. No claim is made that what is found in one tropical area will of necessity apply in all others, and the position will have to be ascertained in each new area. The majority of false positive reactions are probably not due to one single factor but to a multiplicity of different factors.

A plea is made that the finding of a positive serological test for syphilis in patients in the tropics should be followed by the same careful search for evidence of syphilis, or other treponematoses, as is normally given to patients with a similar finding in temperate climates. The practice of automatically disregarding serological positive results in Africans with no active manifestations of syphilis, simply because false positive results are commoner in the tropics, is deprecated. To quote Stokes and James (1949):

There can be no excuse for discarding or minimizing the serological test for syphilis because there are biologic or non-specific positive tests.

I wish to acknowledge my indebtedness to Dr. $\mathrm{H}$. Bollink, Nsadzu Mission Leper Colony, and to Dr. P. G. Peach, Mwami Mission Leper Colony, for their assistance, and to the Director of Medical Services, Northern Rhodesia, for permission to publish this paper.

\section{REFERENCES}

Allison, A., and Dick, A. (1954). Lancet, 2, 364.

Andujar, J. J., Anderson, M. M., and Mazurek, E. E. (1948). Amer. J. clin. Path., 18, 199. 
Babin, F., and Dulaney, A. D. (1945). Amer. J. Hyg., 42, 167.

Badger, L. F. (1931). Publ. Hlth Rep. (Wash.), 46, 957.

Beerman, H. (1945). Amer. J. med. Sci., 209, 525.

Boak, R. A., Miller, J. N., and Carpenter, C. M. (1954). Amer. J. S.ph., 38, 434.

Burney, L. E., Mays, J. R. S., and Iskrant, A. P. (1942). Amer. J. publ. Hlth, 32, 39

Cardon, L., and Atlas, D. H. (1942). Arch. Derm. Syph. (Chicago), 46, 713

Chacko, C. W. (1953). Brit. J. exp. Path., 34, 556.

Chorpenning, F. W. (1953). U.S. armed Forces med. J., 4, 807.

Cooper, G. R., Craig, H. W., and Beard, J. W. (1946). Amer. J. Syph. 30, 555.

Cumming, H. S., Hazen, H. H., Sanford, A. H., Senear, E. E., Simpson, W. M., and Vonderlehr, R. A. (1935). J. Amer. med. Ass., 104, 2083.

Davis, B. D. (1944). Medicine (Baltimore), 23, 359.

De Mello, J. (1948). E. Afr. med. J., 25, 14.

Durel, P., Saussé, A., and Borel, L.-J. (1952). British Journal of Venereal Diseases, 28, 68.

Eagle, H. (1941). Amer. J. Syph., 25, 7.

Editorial (1951). Britisl: Journal of Venereal Diseases, 27, 49.

Editorial (1954). Lancet, 2, 1165.

Evans, A. J. (1954). British Journal of Venereal Diseases, 30, 212.

Falcone, V. H., Harris, A., Olansky, S., Salvado, C., and Cutler, J. C. (1953). Amer. J. Syph., 37, 264.

Guthe, T., and Reynolds, F. (1951). British Journal of Venereal Diseases, 27, 1.

Harrell, E. R. (1953). Amer. J. Syph., 37, 330.

Heywood, C. P. (1952). British Journal of Venereal Diseases, 28, 3.

Hinton, W. A., Stuart, G. O., and Grant, J. F. (1949). Amer. J. Syph., 33, 587.

Hudson, E. H. (1951). British Journal of Venereal Diseases, 27, 174.

Idsoe, O., Guthe, T., Christiansen, S., Krag, P., and Cutler, J. C. (1954). Bull. Wld Hlth Org., 10, 507.

Kahn, R. L. (1950a). "Serology with Lipid Antigen”, p. 24. Williams and Wilkins, Baltimore.

(1950b). Ibid., p. 38.

- (1950c). Ibid., p. 46

(1950d). Ibid., p. 243.

(1950e). Ibid., p. 299.

(1953). J. Amer. med. Ass., 152, 1204

(1954). British Journal of Venereal Diseases, 30, 124.

Kampmeier, R. H. (1946). "Essentials of Syphilology", 2nd ed., p. 348. Blackwell, Oxford.

Kent, J. F., Culwell, W. B., Coatney, G. R., and Cooper, W. C. (1948). J. Lab. clin. Med., 33, 747

Kitchen, S. F., Webb, E. L., and Kupper, W. H. (1939). J. Amer. med. Ass., 112, 1443.

Klein, S. J., Konwaler, B. E., Sears, C., Berke, M., and Leiby, G. M. (1950). Amer. J. Syph., 34, 245.

- and Leiby, G. M. (1948). Ibid., 32, 377.

Kolmer, J. A., and Lynch, E. R. (1953). Amer. J. clin. Path., 23, 854

Kvittingen, J., Cutler, J. C., McCullough, J. C., Rose, E., Ford, V., Tampi, R. B., Sen, S., and Lakshwir, —. (1952). Bull. Wld Hlth Org., 7, 83.

Laird, S. M. (1954). British Journal of Venereal Diseases, 30, 98.

Laurie, W. (1954). Lancet, 2, 801.

Ledbetter, R. K. (1954). Amer. J. Syph., 38, 522.

Lees, R. (1951). British Journal of Venereal Diseases, 27, 127.

Levitan, L., Aragon, H. A., Cutler, J. C., Funes, J. M., Portnoy, J., and Paredes-Luna, A. (1952). Amer. J. Syph., 36, 379.

Macnab, G. M., and Murray, J. F. (1953). S. Afr. med. J., 27, 655.

Magnuson, H. J., and Thompson, F. A. (1949). J. vener. Dis. Inform., 30, 309.

Mahoney, J. F., and Zwally, M. R. (1949). Bull. Wld Hlth Org., 2, 227.

Manson-Bahr, P. H. (1945a). "Manson's Tropical Diseases", 12th ed., p. 86. Cassell, London.

(1945b). Ibid., p. 576.

Mayer, M. (1951). Sem. Hôp. Paris, 27, 1285.

Meinicke, K. (1952). Wien. med. Wschr., 102, 378.

Miller, J. L., Slatkin, M. H., Brodey, M., Wechsler, H. L., and Hill, J. H. (1954). J. Amer. med. Ass., 154, 1241.

- - - Feiner, R. R., Portnoy, J., and Cannon, A. B. (1952a). Ibid., 149, 987.

36, 559.

Moore, J. E. (1949). British Journal of Venereal Diseases, 25, 169.
Moore, J. E., and Mohr, C. F. (1952a). J. Amer. med. Ass., 150, 467. (1952b). Ann. intern. Med., 37, 1156.

Nelson, M. G. (1947). Trans. roy. Soc. trop. Med. Hyg., 41, 127.

Nelson, R. A. (1952). British Journal of Venereal Diseases, 28, 160. (1953). Amer. J. Syph., 37, 1.

, and Mayer, M. M. (1949). J. exp. Med., 89, 369.

-, Zheutlin, H. E. C., Diesendruck, J. A., and Austin, P. G. M. (1950). Amer. J. Syph., 34, 101.

Nielsen, H. A. (1954). Acta derm.-venereol. (Stockh.), 34, 102.

Northern Rhodesia (1951). “ Health Department-Annual Report for the Year 1950." Government Printer, Lusaka, N. Rhodesia. (1954). “African Affairs: Annual Report for 1953." Government Printer, Lusaka, N. Rhodesia.

Olansky, S., Harris, A., and Casey, H. (1954). Publ. Hlth Rep. (Wash.), 69, 521.

- - -

Pangborn, M. C. (1941). Proc. Soc. exp. Biol. (N. Y.), 48, 484.

Pirilä, V. (1954). Acta derm.-venereol. (Stockh.), 34, 341.

Portnoy, J., Ramiro Galvez, A., and Cutler, J. C. (1952). Amer. J. Syph., 36, 566.

Price, I. N. O. (1949). British Journal of Venereal Diseases, 25, 67.

(1954). Ibid., 30, 210.

Rein, C. R. (1952). Amer. J. Syph., 36, 552. , and Elsberg, E. S. (1944). Amer. J. clin. Path., 14, 461.

Kelcec, L. C., Rosenfield, T. M. (1951). Amer. J. Syph., $35,573$.

, and Kent, J. F. (1947). J. Amer. med. Ass., 133, 1001.

, and Kostant, G. H. (1949). Arch. Derm. Syph. (Chicago), $60,217$.

Robinson, H. M., and McKinney, W. W. (1945). J. Amer. med. Ass., $129,667$.

Roy, A. N., Hill, J. H., Gowdey, J. L., Kelcec, L. C., and Rein, C. R. (1953). Amer, J. Syph., 37, 338.

Sachs, S. B., and Selesnick, H. (1953). S. Afr. med. J., 27, 644

Schmidt, H. (1953). British Journal of Venereal Diseases, 29, 84.

-_1954). Acta derm.-venereol. (Stockh.), 34, 159.

Simpson, R. G. (1954). Amer. J. Syph., 38, 422.

Singh, B. (1947). J. Indian Army med. Cps, 3, 186.

-(1949). British Journal of Venereal Diseases, 25, 159.

Smith, D. A. (1950). " Report of a Nutrition and Health Survey in the Kawambwa District." Government Printer, Lusaka, N. Rhodesia.

Stokes, J. H., Beerman, H., and Ingraham, N. R. (1944a). “Modern Clinical Syphilology ”, 3rd ed., p. 80. Saunders, Philadelphia.

$-,-,-(1944$ b). Ibid., p. 87.

, Boerner, F., Hitchens, A. P., and Nemser, S. (1946). J. Amer. med. Ass., 130, 57.

—, and James, G. W. (1949). Amer. J. Syph., 33, 114.

Stout, G. W., Aguirre, F., and Scrimshaw, N. S. (1952). Ibid., 36, 60. , and Cutler, J. C. (1951). J. vener. Dis. Inform., 32, 237.

, Guzmán, M.,and Scrimshaw, N.S.(1952a). Amer. J. Syph.,36, 41. - (1952b). Ibid., 36, 49.

_-, Harris, A., and Olansky, S. (1954). Amer. J. med. Tech., 20, 269. Méndez, J., Guzmán, M., and Scrimshaw, N. S. (1952). Amer. J. Syph., 36, 55.

Talmage, W. R., Dunn, C. W., and Breazeale, E. L. (1946). Bull. U.S. Army med. Dep., 6, 741 .

Taussig, A. E., and Orgel, M. N. (1937). J. Lab. clin. Med., 22, 614.

Thomas, E. W., Landy, S., and de Mello, L. (1950). Amer. J. Syph. 34, 364.

Thompson, F. A., and Magnuson, H. J. (1951). Ibid., 35, 21.

Tompkins, V. N. (1949). N.Y. St. J. Med., 49, 1189.

Wheeler, A. H., Van Goor, P. H. K., and Curtis, A. C. (1954). Amer. J. Syph., 38, 437.

Wilkinson, A. E. (1954). British Journal of Venereal Diseases, $30,144$.

Willcox, R. R. (1949). “ Report on a Venereal Disease Survey of the African in Southern Rhodesia." Department of Health, S. Rhodesia.

- (1952). J. vener. Dis. Inform., 32, 229.

Wills, L., and Bell, M. E. (1951). Lancet, 1, 820.

Wilson, R., and Levin, S. L. (1936). Amer. J. med. Sci., 191, 696.

Wolman, I. J. (1946). Ibid., 212, 280.

World Health Organization (1950). Expert Committee on Venereal Infections. Report on the First Session of the Subcommittee on Serology and Laboratory Aspects, Washington, 1949. Wld Hlth Org. tech. Rep. Ser. No. 14

Zellmann, H. E. (1954). Amer. J. Syph., 38, 506. 